Discussion Paper No. 01-67

\title{
Fair Division with General Equilibrium Effects and International Climate Politics
}

Christoph Böhringer and Carsten Helm

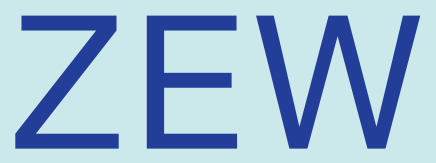

Zentrum für Europäische Wirtschaftsforschung GmbH

Centre for European

Economic Research 
Discussion Paper No. 01-67

\title{
Fair Division with General Equilibrium Effects and International Climate Politics
}

\author{
Christoph Böhringer and Carsten Helm
}

Download this ZEW Discussion Paper from our ftp server:

ftp://ftp.zew.de/pub/zew-docs/dp/dp0167.pdf

Die Discussion Papers dienen einer möglichst schnellen Verbreitung von neueren Forschungsarbeiten des ZEW. Die Beiträge liegen in alleiniger Verantwortung der Autoren und stellen nicht notwendigerweise die Meinung des ZEW dar.

Discussion Papers are intended to make results of ZEW research promptly available to other economists in order to encourage discussion and suggestions for revisions. The authors are solely responsible for the contents which do not necessarily represent the opinion of the ZEW. 


\section{Non-technical summary:}

In this paper, we propose a solution for the fair division of common property resources that supplements the Walrasian solution by lump-sum wealth transfers to assure the adherence of welfare bounds, whose ethical justification rests on commonality of ownership. We apply this Bounded Walrasian Solution (BWS) to the question of burden sharing in the climate change regime using an intertemporal computable general equilibrium model. For a wide range of initial allocations of $\mathrm{CO} 2$ emission rights we find that developing countries should fully participate in emission reduction efforts to increase global efficiency of carbon abatement, but should also be fully compensated for the associated costs. At the same time, BWS reduces emission abatement costs for industrialized countries, which would be moderate even for an instantaneous equal per capital allocation of emission rights.

Our simulations show that the fair division of the gains from exchanging entitlements to the global carbon resource has welfare implications that are as important as the initial allocation of entitlement itself. For rather controversial initial entitlement rules, BWS leads to very similar welfare pattern. This indicates that the importance of the entitlement allocation may actually have been overemphasized as compared to the allocation of the gains from exchanging these entitlement. If one agrees that the ethical judgement that underlie BWS are less controversial than the fair allocation of initial entitlements, this might actually help to facilitate the conflict on burden sharing in climate change negotiations. 


\title{
Fair Division with General Equilibrium Effects and International Climate Politics
}

\author{
Christoph Böhringer* and Carsten Helm ${ }^{\dagger}$
}

November 28, 2001

\begin{abstract}
This paper introduces a solution for the fair division of common property resources in production economies with multiple inputs and outputs. It is derived from complementing the Walrasian solution by welfare bounds, whose ethical justification rests on commonality of ownership. We then apply this solution to the question of burden sharing in the climate change regime, using an intertemporal computable general equilibrium model. For a wide range of initial allocations of $\mathrm{CO}_{2}$ emission rights, we find that developing countries should participate in emission reduction efforts in order to increase their global efficiency, but should also be fully compensated for their incremental abatement costs.
\end{abstract}

Keywords: Fair division, climate change, common property resources, welfare bounds, CGE models.

JEL-classification: D58, D63, Q20

${ }^{*}$ Centre for European Economic Research (ZEW), PO Box 1034 43, 68034 Mannheim, Germany, phone: +49 621 1235-200, fax: +49 621 1235-226, e-mail: boehringer@zew.de.

${ }^{\dagger}$ Humboldt-University Berlin, School of Business and Economics, Spandauer Str. 1, 10178 Berlin, Germany, phone: +49 30 2093-1342, fax: +49 30 2093-1343, e-mail: helm@wiwi.huberlin.de. 


\section{Introduction}

In this paper, we analyze the fair division of an unproduced commodity that is the common property of a group of agents. We formulate welfare bounds for fair division which take account of general equilibrium effects. These criteria are then applied to the fair division of emission abatement burdens in the climate change regime. We show that essentially the same abatement cost pattern may emerge for different initial allocations of emission rights.

The fair division literature usually focuses on economies that are restricted to those goods that must be divided fairly (see Moulin 1995 for an introduction). Often, this is appropriate: if we analyze the classical problem of fairly dividing a cake, for instance, we do not have to worry about the rest of the economy. However, there are problems for which such an approach is less suitable, because the allocation of the commodities to be divided fairly - called 'fair division commodities' in the following - has significant spillover effects to other commodity markets that will also affect agents' welfare. A pertinent example is the allocation of emission abatement cost in the climate change regime.

In the Kyoto Protocol, industrialized countries as listed in Annex B of the Protocol agreed to reduce their 1990 emissions of greenhouse gases by an average of 5.2 per cent during the commitment period 2008-2012. However, there has been widespread consensus that much higher emission reductions will be required in the long run in order to avoid substantial increases in the global mean temperature (Metz, Davidson, Swart, and Pan 2001). Given the potential magnitude of economic adjustment costs induced by stringent global emission constraints, questions of burden sharing will receive increased attention.

For example, the Byrd-Hagel Resolution, passed 95 to 0 votes in the U.S. Senate in 1997, states that "the United States should not be a signatory to any protocol that excludes developing countries from legally binding commitments." ${ }^{1}$ In March 2001, this position was reinforced by U.S. President George W. Bush, who characterized the Kyoto Protocol as 'fatally flawed' and refused to ratify it. Developing countries, on their part, have argued that they carry only minor historical responsibility for the increase in global $\mathrm{CO}_{2}$ concentrations. Therefore, industrialized countries should go ahead with climate protection measures.

How, then, should emission reduction burdens be allocated? In the following, we shall address this question from the normative perspective of fair division theory, which is based on ordinal preference relations and requires neither cardinal nor interpersonal comparability.

As Moulin $(1991,326)$ states, "the normative literature on (ordinal) fair divi-

\footnotetext{
${ }^{1}$ The Byrd-Hagel Resolution, U.S. Senate, 12 June 1997, 105th Congress, 1st Session, Senate Resolution 98.
} 
sion argues almost unanimously in favor of the competitive equilibrium from equal split". This solution satisfies a number equity principles such as individual rationality and envy-freeness for a wide range of problems (Moulin 1990; Young 1994). Not surprisingly, the competitive (or Walrasian) equilibrium also obtains a prominent position in the debate on how to allocate greenhouse gas abatement costs (for a survey see Rose, Stevens, Edmonds, and Wise 1998). More so, Article 17 of the Kyoto-Protocol actually provides for the trading of emission rights, at least among Annex I countries.

Nevertheless, the Walrasian equilibrium has some normative defects if applied to the fair division of common property resources. In particular, common ownership intuitively suggests that one should share the benefits of the resource with the coowners. This idea of solidarity may be violated by the Walrasian equilibrium, which may even give some agents a share that they value more (utilitywise) than the whole common resource (Moulin 1991).

Despite this critique of the Walrasian equilibrium, no clearly superior candidate has emerged. One reason is that a number of desirable fair division criteria have been shown to be incompatible for any division mechanism (e.g., Moulin 1990; Moulin 1995). In this paper, therefore, we will use the Walrasian equilibrium as a starting point. However, we will supplement it with welfare bounds so as to improve its normative appeal. Accordingly, we name our proposal for the fair division of common property resources "Bounded Walrasian Solution".

If applied to climate change, it has some interesting implications. In particular, the most cited argument against allocating tradable emission rights on an equal per capita basis is the potentially large welfare transfers from developed to developing countries. This is avoided by the bounded Walrasian solution. For a wide range of initial allocations of emission rights - including an equal per capita allocation -, it essentially leads to a solution where developing countries are fully compensated for their emission abatement efforts, but do not receive any further transfers.

The paper is structured as follows. In Section 2 we discuss utility bounds for fair division in economies with multiple inputs and outputs. These will form the basis for the bounded Walrasian solution, which we apply to the allocation of emission abatement burdens in the climate change regime. In Section 3 we explain the basic characteristics of our computable general equilibrium model, and continue in Section 4 with the implementation of the bounded Walrasian solution. Section 5 presents the main results, and Section 6 concludes.

\section{Utility bounds in fair division}

Consider an exchange economy in which each agent is initially endowed with an equal per capita share of a common property resource. If exchanges are governed by the 
Walrasian solution, then the utility of individual agents has no finite upper bound (Moulin 1991, 326). For example, if there is one agent with 'eccentric' preferences surrounded by a large number of agents of equal type, then the eccentric agent may keep all the surplus of exchanging the initial endowment - and this surplus may tend towards infinity.

Similarly, with tradable $\mathrm{CO}_{2}$ emission rights, some countries may obtain an income from permit sales that substantially exceeds their emission abatement costs. One may ask 'so what?'. After all, it is quite common that agents achieve a high income for goods that are heavily sought after. However, we are concerned not with ordinary private goods, but with goods that are the common property of several agents. Having an equal per capita entitlement to them is quite a different thing from equal per capita property rights. In the latter case, there would no longer be a common resource.

John Locke (1632 - 1704) argued that the maximum utility that can be obtained from a common resource should be one that arises from one's own usage of the resource, but not from selling shares of it. Starting with the idea that nature in its original state is common property that was given equally by God to all men to be worked and appropriated by them, he writes:

"God has given us all things richly", is the voice of reason confirmed by inspiration. But how far has he given it to us? To enjoy. As much as any one can make use of to any advantage of life before it spoils, so much he may by his labour fix a property in; whatever is beyond this is more than his share, and belongs to others. (Locke 1963)

More recently, Moulin $(1992,1333)$ has argued in similar spirit that "fair division conveys the idea of no subsidization: the presence of other agents who are willing to pay higher monetary transfers than me for consuming the resources should not turn to my advantage." This argument seems particularly justified if the willingness to pay higher monetary transfers is related to efforts to solve a problem that affects all agents - such as climate change.

These are the normative ideas that underlie the stand-alone upper bound. In an exchange economy that is restricted to the fair division commodities, it is defined as an agent's utility if he alone consumes the whole common resource (Moulin 1991; Moulin 1992). ${ }^{2}$ However, in a general equilibrium framework, an agent's utility depends not only on his own use of the common resource, but also on induced adjustments of other agents. For example, an agent may derive little or even no utility from his consumption of a resource, but still benefit via general equilibrium effects from other agents' consumption of it. In this case, the scenario in which he alone consumes the common resource is questionable as an upper bound.

\footnotetext{
${ }^{2}$ It is common to assume free disposal.
} 
To take account of these considerations, we propose to define the upper bound as the highest utility that an agent can attain if he has the right to determine the initial allocation of the common resource. We call this the dictatorial upper bound. Accordingly, the agent may allocate some of the common resource to other agents so as to benefit from the general equilibrium feedback of spillover effects. However, according to the above ideas, he may not charge for that. Note that in a partial equilibrium framework, this definition coincides with the standard stand-alone upper bound.

To formalize this idea, we consider an economy with $I$ agents, $J$ firms and $L$ commodities. Each agent $i=1, \ldots, I$ has rational, continuous, strongly monotone, and convex preferences that are defined on his closed and convex consumption set $X_{i} \subset \mathbb{R}^{L}$. We assume that preferences admit a numerical representation through a concave utility function $u_{i}: X_{i} \rightarrow \mathbb{R}$, and normalize $u_{i}(0)=0$. Each agent $i$ 's vector of initial endowments $\omega_{i}=\left(\omega_{i 1}, \ldots, \omega_{i L}\right) \in \mathbb{R}^{L}$ can be partitioned into two groups. The first group, indexed $l=1, \ldots, M$, are unproduced commodities that are to be divided fairly. They can be consumed or used as an input into production. Hence $M \geq 1$ represents the number of fair division commodities. The second group comprises the other (produced or unproduced) private commodities, which are indexed $l=M+1, \ldots, L$.

Each firm $j=1, \ldots, J$ is characterized by a non-empty, closed and convex production set $Y_{j} \subset \mathbb{R}^{L}$ that satisfies the free-disposal property. Profits of firms accrue to the agents as the stakeholders. Denote by $\theta_{i j} \in[0,1]$ an agent $i$ 's ownership share in firm $j$, and let $\theta_{i}=\left(\theta_{i 1}, \ldots, \theta_{i J}\right) \in \mathbb{R}^{J}$. Accordingly, $\sum_{i} \theta_{i}$ is the unit vector. Thus, we can summarize the mixed private-common ownership economy by $\mathcal{E}=\left(\left\{X_{i}, u_{i}\right\}_{i=1}^{I},\left\{Y_{j}\right\}_{j=1}^{J},\left\{\omega_{i}\right\}_{i=1}^{I},\left\{\theta_{i}\right\}_{i=1}^{I}\right)$.

An allocation $(x, y)=\left(x_{1}, \ldots, x_{I}, y_{1}, \ldots, y_{J}\right)$ is a specification of a consumption vector $x_{i}=\left(x_{i 1}, \ldots, x_{i L}\right) \in X_{i}$ for each consumer and a production vector $y_{j}=$ $\left(y_{j 1}, \ldots, y_{j L}\right) \in Y_{j}$ for each firm defined over the $L$ commodities. The set of feasible allocations $A=\left\{(x, y): \sum_{i=1}^{I} x_{i}=\sum_{j=1}^{J} y_{j}+\sum_{i=1}^{I} \omega_{i}\right\}$ is assumed to be nonempty and compact. A solution is a correspondence $F$ that associates with every economy $\mathcal{E}$ a subset of feasible allocations $(x, y) \in F(\mathcal{E})$.

Definition 1 Let $x_{k}^{F}$ denote an agent $k$ 's consumption vector induced by a solution $F(\mathcal{E})$, let $p=\left(p_{1}, \ldots, p_{L}\right)$ be a price vector, and superscripts ${ }^{*}$ indicate equilibrium levels. Furthermore, denote an agent $k$ 's choice of another agent $i$ 's endowment with the fair division commodities by $\omega_{i}^{k}=\left(\omega_{i l}^{k}\right)_{l=1}^{M} \in \mathbb{R}^{M}$. A solution $F$ satisfies the dictatorial upper bound if for each agent $k, k=1, \ldots, I$, and every economy $\mathcal{E}: u_{k}\left(x_{k}^{F}\right) \leq u_{k}^{D}\left(x_{k}^{*}\right)$, where

$$
\begin{aligned}
u_{k}^{D}\left(x_{k}^{*}\right)= & \max _{\left\{\left(\omega_{i}^{k}\right)_{i=1}^{I}\right\}}\left\{u_{k}\left(x_{k}^{*}\right)\right\} \text { such that } \\
& p y_{j}^{*} \geq p y_{j} \forall y_{j} \in Y_{j}, \forall j=1, \ldots, J .
\end{aligned}
$$




$$
\begin{gathered}
u_{i}\left(x_{i}^{*}\right) \geq u_{i}\left(x_{i}\right) \forall x_{i} \in B_{i}, \forall i=1, \ldots, I, \\
B_{i}=\left\{x_{i} \in X_{i}: p x_{i} \leq p \omega_{i}+\sum_{j=1}^{J} \theta_{i j} p y_{j}^{*}\right\} . \\
\sum_{i=1}^{I}\left(x_{i l}^{*}\right)_{l=M+1}^{L}-\sum_{j=1}^{J}\left(y_{j l}^{*}\right)_{l=M+1}^{L}=\sum_{i=1}^{I}\left(\omega_{i l}\right)_{l=M+1}^{L} . \\
\left(x_{i l}^{*}\right)_{l=1}^{M}-\sum_{j=1}^{J} \theta_{i j}\left(y_{j l}^{*}\right)_{l=1}^{M} \leq\left(\omega_{i l}^{k}\right)_{l=1}^{M} \quad \forall i=1, \ldots, I .
\end{gathered}
$$

Conditions (2) to (4) are the standard requirements for a Walrasian equilibrium of profit maximization, utility maximization subject to the budget constraint, and market clearing. More precisely, an allocation $\left(x^{*}, y^{*}\right)$ and a price vector $p$ would constitute a Walrasian equilibrium if they satisfied conditions (2) and (3) subject to $\sum_{i=1}^{I} x_{i}^{*}=\sum_{j=1}^{J} y_{j}^{*}+\sum_{i=1}^{I} \omega_{i}$. We denote the Walrasian allocation for later reference by $\left(x^{W}, y^{W}\right)$.

The crucial expression for the dictatorial upper bound is (5). It states that an agent $i$ 's consumption of the fair division commodities and their use as an input into production - calculated as firms' input of the fair division commodities weighted by $i$ 's ownership shares - may not exceed the initial endowment as determined by agent $k$. Hence, the fair division commodities are exempted from Walrasian trading.

The dictatorial upper bound reflects that fair division problems are often framed as 'manna falling from heaven' that has to be divided fairly. Accordingly, there is something to allocate that has not been consumed previously. For environmental problems, however, the usual scenario is that a common resource has been overused because it was considered a free resource, and now its usage for consumption and production must be restricted. Therefore, the original unrestricted usage of the common resource is a further upper bound candidate. We call this the free access upper bound. Applied to climate change, this coincides with the business-as-usual scenario without any explicit emission reduction measures. Hence, the free access upper bound assures that no country benefits at the expense of other countries' emission reduction burdens, again reflecting the solidarity ideal inherent in fair division.

The main shortcoming of the free access upper bound is that it includes the benefits from an overuse of the common resource in the free access scenario - both direct ones from its domestic use and indirect ones via spillover effects of its use by other agents. If the overuse and the associated benefits are very high, then the free access upper bound may also be excessively high. Therefore, it would be of little guidance for fairly dividing a resource that is small compared to its usage in the free access scenario. However, for the emission scenarios that we consider later on, this is not the case. 
Besides upper bounds, also lower bounds have always played a prominent role in fair division theory. Actually, the oldest fair division axiom belongs to this category: Steinhaus' (1948) criterion of individual rationality that each agent should be guaranteed at least the utility from consuming his entitlement to a common resource. In a mixed private-common ownership economy with general equilibrium effects, however, this criterion is not well defined because an agent's utility from consuming his entitlement to a common resource depends on the behavior of the other agents.

One possibility would be to impose certain assumptions with respect to this behavior. For example, one could define the lower bound as the utility that arises if all agents use their entitlement to the common resource for their own consumption and production. One may ask, however, why an agent should be entitled to gains that may arise via general equilibrium effects from the other agents' waiver to trade their initial entitlements. Similar objections could be raised against any other assumption about the behavior of the other agents. ${ }^{3}$

For this reason, we abstain from formulating an explicit lower bound. However, the following proposition shows that there exists a solution which assures those agents who do not receive their upper bound utility at least their utility at the Walrasian equilibrium. Implicitly, therefore, we have incorporated a lower bound, even though it has not been derived from explicit normative principles. Note also that a lower bound that gives every agent more than his utility at the Walrasian equilibrium could never be satisfied.

Proposition 1 Let $\left(u_{1}^{U B}, \ldots, u_{I}^{U B}\right)$ be a (non-feasible) profile of utility upper bounds. There exists a Pareto efficient allocation $(x, y)$ that satisfies the utility upper bound and that assures every agent who does not receive his utility upper bound at least his utility at the Walrasian equilibrium, i.e.

$$
\exists(x, y): u_{i}(x) \leq u_{i}^{U B} \text { and } u_{i}(x) \geq \min \left\{u_{i}^{U B}, u_{i}\left(x^{W}\right)\right\}, i=1, \ldots, I .
$$

Proof. We define by $S=\left\{i, i=1, \ldots, I: u_{i}\left(x_{i}^{W}\right)>u_{i}^{U P}\right\}$ the set of agents whose Walrasian utility exceeds their utility upper bound. Furthermore, we denote by $U=\left\{\left(u_{1}, \ldots, u_{I}\right) \in \mathbb{R}^{I}\right.$ : there exists a feasible allocation $(x, y)$ such that $u_{i} \leq$ $\left.u_{i}\left(x_{i}\right), i=1, \ldots, I\right\}$ the utility possibility set, and by $U P=\left\{\left(u_{1}, \ldots, u_{I}\right) \in U\right.$ : there is no $\left(u_{1}^{\prime}, \ldots, u_{I}^{\prime}\right) \in U$ such that $u_{i}^{\prime} \geq u_{i}$ for all $i$ and $u_{i}^{\prime}>u_{i}$ for some $\left.i\right\}$ the Pareto frontier of $U$.

Since the Walrasian allocation $\left(x^{W}, y^{W}\right)$ is Pareto efficient by the First Fundamental Theorem of Welfare Economics, $\left(u_{1}\left(x_{1}^{W}\right), \ldots, u_{I}\left(x_{I}^{W}\right)\right) \in U P$. Let $\left(\hat{u}_{1}, \ldots, \hat{u}_{I}\right)$ be a utility profile such that $\hat{u}_{i}=u_{i}^{U B}$ for all $i \in S$ and $\hat{u}_{i}=u_{i}^{W}$ for all $i \notin S$. By definition of set $S,\left(\hat{u}_{1}, \ldots, \hat{u}_{I}\right) \in U \backslash U P$ if $S \neq \emptyset$. Geometrically, we simply move

\footnotetext{
${ }^{3}$ Note the contrast to the dictatorial upper bound, where the agent under consideration dictates the other agents allocation of the fair division commodities.
} 
into the interior of the utility possibility set by reducing the utility of agents $i \in S$ to levels $u_{i}^{U B}$, while holding the other agents utility fixed at $u_{i}\left(x_{i}^{W}\right)$. Our assumptions on preferences assure that $U$ is closed and bounded above. Hence, by continuity of preferences, there obviously exists a feasible utility vector on the boundary of the utility possibility set such that $u_{i}=\hat{u}_{i}$ for all $i \in S$ and $u_{i} \geq \hat{u}_{i}$ for all $i \notin S$. Finally, with strongly monotonic preferences, any such solution is Pareto efficient.

In Section 4, we will propose a specific way of moving from the utility profile $\left(\hat{u}_{1}, \ldots, \hat{u}_{I}\right)$ to the Pareto frontier, which is essentially by giving all agents $i \notin S$ equal lump-sum transfers. However, in the next section we will first introduce the computable general equilibrium model that we use for the empirical analysis of carbon dioxide abatement.

\section{A computable general equilibrium model for the analysis of carbon dioxide abatement}

Our multi-sector, multi region model of the world economy features 10 regions which are linked through bilateral trade flows. The spatial aggregation covers regions that are central to the greenhouse gas policy debate (see Table 1). The sectors have been chosen so as to capture key dimensions in the analysis of abatement of carbon dioxide (as the most important greenhouse gas) such as differences in carbon intensities across fossil fuels and the substitutability across energy goods and nonenergy goods.

In particular, the economic structure of each region consists of 4 production sectors: one non-energy macro good sector and three fossil fuel sectors (coal, crude oil and natural gas). Their outputs are demanded by intermediate production, exports, investment and a representative consumer. More specifically, this economic structure represents the economy as introduced in Section 2, where the $I$ agents are

Table 1: Overview of regions

\begin{tabular}{|c|c|c|c|}
\hline Label & Long name & Label & Long name \\
\hline$\overline{\mathrm{AFR}}$ & Sub-Saharan Africa & $\mathrm{CHN}$ & China \\
\hline IDI & India & LAM & Latin America and the Caribbean \\
\hline MEA & Middle East and North Africa & NAM & North America (USA and Canada) \\
\hline $\mathrm{PAO}$ & $\begin{array}{l}\text { Pacific OECD (Japan, } \\
\text { Australia, New Zealand) }\end{array}$ & PAS & Other Pacific Asia \\
\hline REC & $\begin{array}{l}\text { Reforming economy countries } \\
\text { (newly independent states } \\
\text { of the former Soviet Union, } \\
\text { Central and Eastern Europe) }\end{array}$ & WEU & Western Europe \\
\hline
\end{tabular}


given as representative consumers in each region, and the $J$ firms are captured as production sectors. Furthermore, the $L$ commodities consist of primary production factors capital and labor, the outputs by the production sectors, and carbon dioxide - the fair division commodity - which is associated with the use of fossil energy in intermediate production and final consumption.

The issue of long-term carbon abatement requires the addition of a dynamic component. Only an intertemporal model setting with markets linked through time provides the appropriate framework for capturing the long-term impacts of policy measures on savings and investments, i.e. future capital stocks. Below, we provide a non-technical description. ${ }^{4}$

Producers and representative consumers behave according to the competitive paradigm, in the sense that they take market prices as given. Their consumption and investment decisions are based on rational point expectations of future prices, thus we assume 'perfect foresight' (see Manne and Richels (1992) for a discussion).

Entrepreneurs choose investment in order to maximize the present value of their firms. In each region, production of the non-energy macro good is captured by an aggregate production function which characterizes technology through transformation possibilities on the output side (between production for domestic and export markets) and substitution possibilities on the input side (between alternative combinations of inputs). On the output side, production is split between goods produced for domestic markets and goods produced for export markets subject to a constant elasticity of transformation. On the input side, capital, labor and an energy aggregate of fossil fuels trade off with a constant elasticity of substitution (CES). Production of the energy aggregate is described by a CES function which reflects substitution possibilities for different fossil fuels (i.e. coal, gas, and oil). Fossil fuels are produced from fuel-specific resources and the non-energy macro good subject to a CES technology.

The representative household in each region chooses to allocate lifetime income across consumption in different time periods in order to maximize lifetime utility. In each period, households face the choice between current consumption and future consumption, which can be purchased via savings. The trade-off between current consumption and savings is given by a constant intertemporal elasticity of substitution. Households demand an aggregate consumption good which is a CES composite of the non-energy macro good and a household-specific energy aggregate.

Output is divided between consumption (incl. exports and intermediate demand) and investment, which augments the (depreciated) capital stock in the next period. Investment takes place until its marginal returns equal the marginal cost of capital formation. These rates of return are determined by a uniform and endogenous

\footnotetext{
${ }^{4}$ The algebraic formulation of the generic intertemporal model can be downloaded from ftp://ftp.zew.de/pub/zew-docs/div/fair.pdf.
} 
world interest rate such that the marginal productivity of a unit of investment and marginal utility of a unit of consumption is equalized within and across countries.

Following Armington (1969), domestic, imported and exported varieties of the non-energy goods are distinguished by origin. The Armington aggregation function provides a constant elasticity of substitution between domestic and imported varieties of the non-energy good for all buyers in the domestic market. With respect to trade in energy, fossil fuels from different regions are treated as perfect substitutes, which implies that we use net trade data with no cross-hauling. International capital flows reflect borrowing and lending at the world interest rate, and are endogenous subject to an intertemporal balance of payments constraint: there is no change in net indebtedness over the entire model horizon.

Finally, there are backstop technologies in each region for producing the industrial energy aggregate and the household energy aggregate. The backstop technology defines the price for a carbon-free energy source in infinite supply (e.g. photovoltaic, fuel cells) and provides an upper limit on the marginal costs of reducing carbon emissions. The backstops are produced in each region through the employment of the region's non-energy macro good.

Data from two different sources are combined to calibrate parameters of the functional forms from a given set of quantities, prices and elasticities. The first source is the GTAP database (McDougall, Elbehri, and Truong 1998), which includes detailed input-output tables for 45 regions and 50 sectors as well as a world trade matrix with bilateral trade flows for all sectors and regions. The other source is the IEA energy statistics (International Energy Agency 1996) that provide physical energy flows and energy prices for industrial and household demands. Reconciliation of these data sources involves replacement of GTAP's aggregate input-output monetary values for energy supply and demand with physical energy flows and energy prices as given in the IEA's energy statistics (Rutherford and Paltsev 2000). The major advantage of doing so is that implicit marginal abatement cost curves for carbon emissions, and hence the cost evaluation of carbon emission constraints, are based on real energy flows rather than aggregate monetary data. This strengthens the credibility of the quantitative results.

For the baseline calibration of our multi-region dynamic CGE model we incorporate IIASA/WEC projections on the future development of GDP and fossil fuel production for the 21st century differentiated by countries (IIASA 1998). Table 2 summarizes the central values for key elasticities employed for the core simulations. 
Table 2: Overview of key elasticities

\begin{tabular}{|c|c|c|}
\hline Type of elasticity & Description & Central Value \\
\hline \multirow{6}{*}{$\begin{array}{l}\text { Armington elasticity } \\
\text { of substitution }\end{array}$} & Degree of substitutability & \\
\hline & - Between macro imports & \\
\hline & from different regions & 2 \\
\hline & - Between the import aggregate & \\
\hline & and the domestically & 1 \\
\hline & produced macro good & \\
\hline \multirow[t]{2}{*}{$\begin{array}{l}\text { Armington elasticity } \\
\text { of transformation }\end{array}$} & $\begin{array}{l}\text { Degree of substitutability between } \\
\text { macro good produced for the }\end{array}$ & \\
\hline & $\begin{array}{l}\text { domestic market and macro good } \\
\text { destined for the export market }\end{array}$ & 2 \\
\hline \multirow{3}{*}{$\begin{array}{l}\text { Price elasticity of } \\
\text { fossil fuel supply }\end{array}$} & Degree of response of & 1 (coal), \\
\hline & international fossil fuel supply to & $4($ gas $)$ \\
\hline & changes in fossil fuel price & 8 (oil) \\
\hline \multirow{4}{*}{$\begin{array}{l}\text { Elasticity of substitution } \\
\text { between non-energy and } \\
\text { energy composite in production } \\
\text { and final demand }\end{array}$} & This value increases linearly over & \\
\hline & time to reflect empirical & 0.2 (short run: 2000) \\
\hline & short-run and long-run & 0.8 (long run: 2050 ) \\
\hline & adjustment costs (Lindbeck 1983) & \\
\hline \multirow{2}{*}{$\begin{array}{l}\text { Interfuel elasticity } \\
\text { of substitution }\end{array}$} & Degree of substitutability between & 0.5 (final demand) \\
\hline & fossil fuels (fuel switching) & $2^{a}, 1^{b}$ (industry) \\
\hline
\end{tabular}

\section{The bounded Walrasian solution to carbon diox- ide abatement}

In the introduction, we mentioned the widespread support that the Walrasian solution has received in the literature on (ordinal) fair division. However, we also pointed out some of its normative defects. To take them at least partly into account, we proposed to supplement the Walrasian solution with an upper bound on each individual agent's utility.

In particular, we suggested that potential violaters of their upper bound utility should receive precisely this upper bound utility. For the other agents, we showed that there are usually many Pareto efficient solutions that give them a utility between their utility at the Walrasian equilibrium and their upper bound utility. As our analysis is exclusively driven by fairness issues, it is natural to treat these agents in an equal way. Still, this leaves open the question of how to actually operationalize the idea of equal treatment. Here, we follow the resourcist approach (Dworkin 1981) by giving these agents equal lump-sum wealth transfers, subject to the constraint that these transfers do not lift them above their utility upper bound.

In particular, the constraint implementing the upper utility bound is

$$
u_{i} \leq u_{i}^{U B} \quad \perp m_{i},
$$


where $u_{i}^{U B}$ is the upper bound intertemporal welfare index for region $i, u_{i}$ is the intertemporal welfare index for region $i$, and $m_{i}$ is the complementary endogenous (intertemporal) payment of region $i$ to keep welfare below upper bound levels. If a region's welfare increases above the level of the upper bound, the constraint binds which implies that $m_{i}$ is no longer zero. The induced transfers of regions with a binding upper bound are used for compensation of other regions on an equal per capita basis (with populations being weighted over time).

For the specific case of climate change, the free access upper bound seems to better reflect the typical framing of the problem and ongoing political discussions than the dictatorial upper bound. In addition, we show that the main defect of the free access upper bound - excessively high upper bounds - is of minor relevance in our empirical example. Therefore, we implement the free access upper bound in our simulations. This restricts the individual region's welfare by the scenario without any explicit emission reduction measures. ${ }^{5}$

Furthermore, the application of this bounded Walrasian solution to climate change requires the preceding specification of entitlements to carbon dioxide emissions, i.e. of $\omega_{i 1}$. The proposals range from equal (historical) per capita entitlements (see Kverndokk 1995) to an allocation in proportion to current emission patterns. Another common proposal is to use multiple criteria - such as GDP, historical emissions and population - and to weigh them such that indicators expressing the status quo are emphasized initially, while those that are perceived as more fair become increasingly important in the course of time (e.g., Cline 1992, 353). We abstain from discussing the ethical aspects of these divergent views (see Helm and Simonis 2001). However, we show below that the effect of applying a fair division solution like the bounded Walrasian solution - may actually dominate the effect of different entitlement specifications.

For the sake of parsimony, we restrict our policy simulations to two prominent entitlement allocations. The first one is gradual convergence (COV) of entitlements from current emission patterns to an equal per capita division of the desired target level in the target year (Grubb and Sebenius 1992). To define the target year, we assume that global carbon emissions are to be reduced by 25 per cent in 2050 relative to their 1990 level. This coincides with recent requests by the International Panel on Climate Change (IPCC) for long-term abatement requirements (Metz, Davidson, Swart, and Pan 2001).

More specifically, per capita emission rights of country $i$ in year $t$ are a weighted average of per capita emissions in 2000, denoted $\omega_{i 1}(2000)$ and the uniform per capita emission rights in 2050, denoted $\omega_{i 1}(2050)$ :

\footnotetext{
${ }^{5}$ Furthermore, implementation of the dictatorial upper bound would require to formulate the general equilibrium model (formally defined as systems of weak inequalities) as an explicit mathematical program subject to equilibrium constraints (MPEC). This may cause severe numerical solving problems for large-scale models (Luo, Pang, and Ralph 1996).
} 
Table 3: HEV in lifetime income (\% change from BaU)

\begin{tabular}{lrrr||rrr}
\hline & Scenario: & COV & Scenario: & EPC & \\
& NTR & WALRAS & BWS & NTR & WALRAS & BWS \\
\hline AFR & -2.07 & 17.04 & 0 & -3.72 & 26.82 & 0 \\
CHN & -3.02 & -1.08 & 0 & -2.98 & 1.29 & 0 \\
IDI & 0.25 & 17.28 & 0 & 0.38 & 26.82 & 0 \\
LAM & -1.13 & 0.38 & 0 & -2.12 & 1.54 & 0 \\
MEA & -3.07 & 2.56 & 0 & -5.87 & 4.26 & 0 \\
NAM & -3.20 & -2.68 & -2.08 & -9.62 & -4.04 & -2.61 \\
PAO & -1.46 & -1.21 & -0.78 & -3.51 & -1.61 & -0.66 \\
PAS & -0.15 & 0.16 & 0 & -0.24 & 1.07 & 0 \\
REC & -9.76 & -8.82 & -1.74 & -19.36 & -12.16 & 0 \\
WEU & -1.72 & -1.40 & -0.85 & -4.34 & -1.87 & -0.62 \\
WORLD & -2.26 & -0.99 & -1.02 & -5.65 & -1.08 & -1.04 \\
\hline
\end{tabular}

$$
\omega_{i 1}(t)=\frac{50-(t-2000)}{50} \omega_{i 1}(2000)+\frac{t-2000}{50} \omega_{i 1}(2050) .
$$

The total carbon limit for a country in a certain year is obtained by multiplying the per capita emission rights by the country's population in that year, which is taken from exogenous population projections (United Nations 1996). Adding the carbon limits across countries defines the global carbon limit.

The second entitlement allocation that we analyze is the equal per capita (EPC) rule: the global carbon resource is distributed across regions in proportion to their respective population. We impose the global emission trajectory of the scenario COV also upon the scenario EPC to assure their consistent comparison.

We report the economic implications of alternative entitlement rules as compared to a business-as-usual (BaU) reference where no emission constraints apply, i.e. the shadow price on the global carbon resource (sink) is zero and there is no need for dividing the 'abundant' fair division commodity. Table 3 summarizes the inframarginal costs of the global emission constraint induced for scenarios COV and EPC measured as a percentage of Hicksian equivalent variation (HEV) in lifetime income. Note that damages from climate change are completely excluded from welfare calculations. ${ }^{6}$

For each entitlement scenario we distinguish three cases. The case NTR reflects a regime where a country's carbon emissions from domestic production and consumption activities are restricted to its initial entitlements; thus there is no international emission trading. The other two cases allow for trading but employ a

\footnotetext{
${ }^{6}$ Implicitly, we assume that they may be governed by a separate compensation solution.
} 


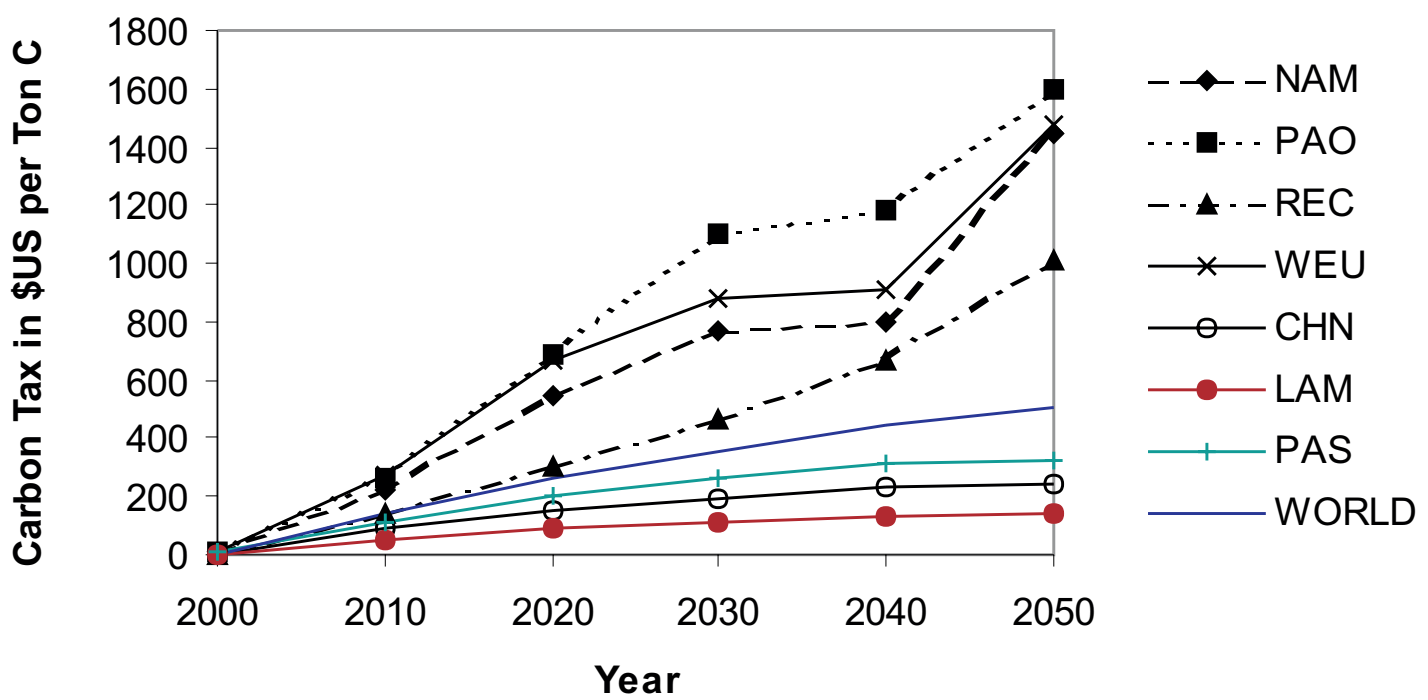

Figure 1: Carbon taxes under NTR for COV

different mechanism for the distribution of efficiency gains. These are the Walrasian solution (WALRAS) and the bounded Walrasian solution (BWS).

\section{$5 \quad$ Interpretation of results}

Much of the debate on fair burden sharing in the climate change regime has focused on the allocation of emission entitlements. Although this is certainly a central question, the results of our simulations illustrate that other issues are equally important for the size of emission abatement costs and their allocation across regions.

The first issue, which is relatively well known in the literature, is the tradability of emission entitlements. In both scenarios, global abatement cost increase dramatically without trading due to the large differences in marginal abatement costs across countries for the NTR case (see Figures 1 and 2). Furthermore, even developing countries that are not obliged to abate emissions under NTR - since their entitlements exceed their demand - may face substantial welfare changes (see regions AFR, MEA, and IDI in Table 3). The reason for this are spillovers via changes in international prices, i.e. terms of trade effects that stem from economic adjustment of other regions (Böhringer and Rutherford 2001).

In this respect, the most important effect are changes on international fuel markets. The cutback in global demand for fossil fuels due to carbon emission constraints implies a significant drop of their prices, providing economic gains to fossil 


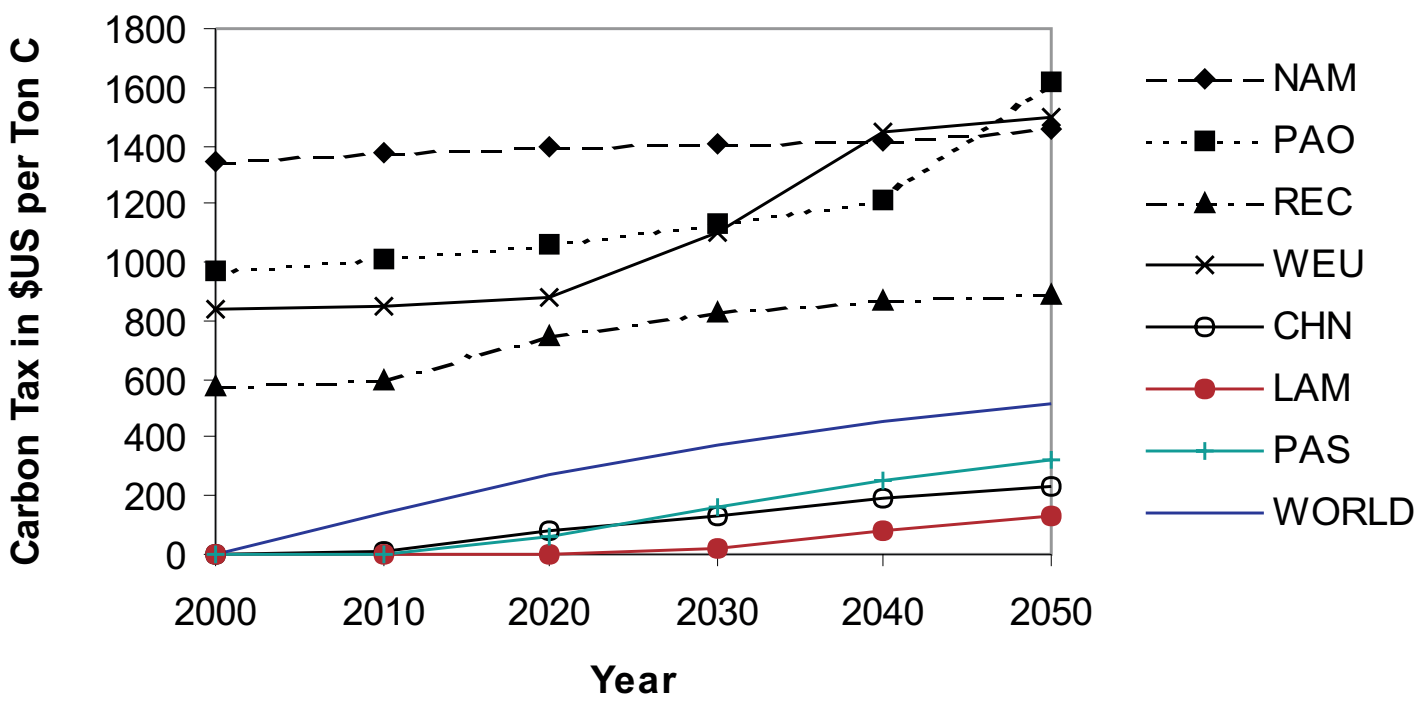

Figure 2: Carbon taxes under NTR for EPC

fuel importers and losses to fossil fuel exporters.

The economic implications of international price changes on non-energy markets are more complex. Higher energy costs implied by carbon taxes raise prices of nonenergy goods (particularly energy-intensive goods) produced in abating countries. Countries that import these goods suffer from higher prices to the extent that they can not substitute away towards cheaper imports of non-abating countries. The ease of substitution - captured by the Armington elasticity - not only determines the implicit burden shifting of carbon taxes via non-energy exports from abating countries, but also the extent to which non-abating countries achieve a competitive advantage vis-à-vis abating exporters.

The gain in market shares caused by substitution effects may be partially offset by an opposite scale effect: Due to reduced economic activity and income effects, import demand declines in the industrialized world, and this exerts a downward pressure on the prices of developing country exports. On average, non-abating regions or countries with very low carbon taxes gain comparative advantage on nonenergy markets. However, this may not be large enough to offset potentially negative spillovers from international fuel markets.

These mechanisms explain why AFR and MEA, although not facing binding emission constraints over the entire time span, experience significant welfare losses: The imports of these countries become more expensive because of high abatement costs in the supplier countries. In addition, reduced import demand by the indus- 
trialized world, where economic activity and income drops substantially, exerts a downward pressure on the prices of exports from AFR and MEA (in particular, revenues from fossil fuel exports decline). IDI, on the other hand, perceives termsof-trade gains, mainly due to reduced expenditure for fossil fuel imports. These mechanisms also explain why most developing countries have a lower welfare in the EPC scenario than in the COV scenario, although the former gives them a substantially higher share of emission entitlements.

This picture changes fundamentally with the trading of carbon dioxide emissions on competitive markets, as can be seen from the case WALRAS in Table 3. In particular, those regions with no or only low carbon taxes under NTR benefit from the huge additional income from their sales of emission rights (e.g. AFR, IDI, and MEA). Under EPC all developing countries will even exceed their BaU welfare levels, i.e. they benefit from global abatement.

This brings us to the second main finding, namely that the fair division of the gains from exchanging entitlements has welfare implications that are as important as the initial allocation of entitlements itself. In particular, supplementing the Walrasian solution by the free access upper bound reduces the partly huge welfare mentioned above. At the same time, it reduces the economic costs of industrialized countries.

Nevertheless, developing countries are fully compensated for their abatement cost with the Bounded Walrasian solution (BWS). Furthermore, the welfare induced by BWS is similar in both scenarios, COV and EPC; maybe with the exception of the reforming economy countries (REC). ${ }^{7}$ Of course, this is not the case for all entitlement allocations. For example, with grandfathered emission rights, the upper bound might not become binding, so that the Walrasian and the bounded Walrasian solution would induce the same outcomes. Obviously, this outcome would be quite different than the one with equal per capita emission rights.

Finally, we observe that welfare differences under COV and EPC are considerably larger for the Walrasian solution than for the bounded Walrasian solution. This again indicates that the importance of the entitlement allocations may actually have been overemphasized as compared to the allocation of the gains from exchanging these entitlements. If one agrees that the ethical judgements that underlie the bounded Walrasian solution are less controversial than the fair allocation of initial entitlements, this might actually help to facilitate the conflict on burden sharing in climate change negotiations.

\footnotetext{
${ }^{7}$ The reason for this is that per capita income transfers under EPC are large enough to fully compensate REC for its abatement costs (note that REC's BaU income is relatively low compared to other developed countries that also receive transfers).
} 


\section{Concluding remarks}

In this paper, we have proposed a solution for the fair division of common property resources that supplements the Walrasian solution by lump-sum wealth transfers to assure the adherence of lower and upper welfare bounds. For the two scenarios that have been analyzed, this has substantial effects on the distribution of emission abatement costs. The bounded Walrasian solution entails the full participation of developing countries in emission abatement efforts, but compensates them for associated costs. At the same time, it reduces emission abatement costs for industrialized countries, which would be moderate even for an instantaneous equal per capita allocation of emission rights.

Interestingly, the full compensation of developing countries resembles the rules of the Montreal Protocol for the protection of the ozone layer, which has generally been praised for its fairness (Benedick 1998). Even though our analysis has been purely normative, this indicates that the proposed solution might actually not be so quixotic after all. Nevertheless, the design of a mechanism for actually implementing the proposed solution has not been addressed in this paper. This remains an open area of further research.

\section{References}

Armington, P. S. (1969). A theory of demand for products distinguished by place and production. IMF Staff Papers 16, 159-178.

Benedick, R. E. (1998). Ozone Diplomacy. New Directions in Safeguarding the Planet (2nd ed.). Cambridge, Mass.: Harvard University Press.

Böhringer, C. and T. Rutherford (2001). Carbon abatement and international spillovers. Environmental and Resource Economics. Forthcoming.

Cline, W. (1992). The Economics of Global Warming. Washington, D.C.: Institute for International Economics.

Dworkin, R. (1981). What is equality? Part II: Equality of resources. Philosophy and Public Affairs 10, 283-345.

Grubb, M. and J. Sebenius (1992). Participation, allocation, and adaptability in international tradable emission permits systems for greenhouse gas control. In OECD (Ed.), Climate Change: Designing a Tradable Permit System. Paris: OECD.

Helm, C. and U. E. Simonis (2001). Distributive justice in international environmental policy. Environmental Values 10(1), 5-18.

IIASA (1998). IIASA/WEC global energy perspectives. http://www.iiasa.ac.at. 
International Energy Agency (1996). Energy Prices and Taxes: Energy Balances of $O E C D$ and Non-OECD Countries. Paris: IEA publications.

Kverndokk, S. (1995). Tradable $\mathrm{CO}_{2}$ emission permits: Initial distribution as a justice problem. Environmental Values 4, 129-148.

Lindbeck, A. (1983). The recent slowdown of productivity growth. Economic Journal 93(369), 13-34.

Locke, J. (1690/1963). Two Treatises of Civil Government. Cambridge, UK: Cambridge University Press.

Luo, Z.-Q., J.-S. Pang, and D. Ralph (1996). Mathematical programs with equilibrium constraints. Cambridge, U.K.: Cambridge University Press.

Manne, A. and R. Richels (1992). Buying greenhouse insurance: The economic costs of $\mathrm{CO}_{2}$ emission limits. Cambridge, M.A.: MIT Press.

McDougall, R. A., A. Elbehri, and T. P. Truong (1998). Global Trade, Assistance and Protection: The GTAP \& Data Base. West Lafayette: Center for Global Trade Analysis, Purdue University.

Metz, B., O. Davidson, R. Swart, and J. Pan (Eds.) (2001). Climate Change 2001: Mitigation. Contribution of Working Group III to the Third Assessment Report of the Intergovernmental Panel on Climate Change. Cambridge, U.K.: Cambridge University Press.

Moulin, H. (1990). Fair division under joint ownership. Social Choice and Welfare $7,149-170$.

Moulin, H. (1991). Welfare bounds in the fair division problem. Journal of Economic Theory 54(2), 321-337.

Moulin, H. (1992). An application of the Shapley value to fair division with money. Econometrica 60(6), 1331-1349.

Moulin, H. (1995). Cooperative Microeconomics. A Game-theoretic Introduction. Princeton, N.J.: Princeton University Press.

Rose, A., B. Stevens, J. Edmonds, and M. Wise (1998). International equity and differentiation in global warming policy. Environmental $\&$ Resource Economics 12, 25-51.

Rutherford, T. and S. Paltsev (2000). GTAP-energy in GAMS. Working Paper 00-2. University of Colorado.

Steinhaus, H. (1948). The problem of fair division. Econometrica 16, 101-104.

United Nations (1996). World Population Prospects: The 1996 Revision. New York: United Nations Publications. 
Young, H. P. (1994). Equity in Theory and Practice. Princeton, N.J.: Princeton University Press. 